\begin{tabular}{|c|c|}
\hline Title & 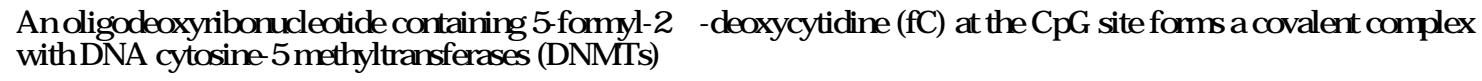 \\
\hline Author(s) & Sato, Kousuke; Kawamoto, Kyoji; Shimamura, Shintaro; Ichikawa, Satoshi; Matsuda, A kira \\
\hline Citation & $\begin{array}{l}\text { Bioorganic \& Medicinal Chemistry Letters, 26(22), 5395-5398 } \\
\text { https://doi.org/10.1016/.bmcl.2016.10.040 }\end{array}$ \\
\hline Issue Date & 2016-11-15 \\
\hline Doc URL & http:/hdl .handle.net/2115/71972 \\
\hline Rights & $\begin{array}{l}\text { @ 2016. This manuscript version is made available under the CC-BY-NC-ND } 4.0 \text { license } \\
\text { http://creativecommons.org/icenses/by-nc-nd/4.0/ }\end{array}$ \\
\hline Rights(URL) & http://creativecommons.org/icenses/by-nc-nd/4.0/ \\
\hline Type & article (author version) \\
\hline File Information & manuscript.pdf \\
\hline
\end{tabular}

Instructions for use 


\title{
An oligodeoxyribonucleotide containing 5-formyl-2'-deoxycytidine (fC) at the CpG site forms a covalent complex with DNA cytosine-5 methyltransferases (DNMTs)
}

\author{
Kousuke Sato ${ }^{\text {a }}$ Kyoji Kawamoto ${ }^{\text {a }}$, Shintaro Shimamura ${ }^{b}$, Satoshi Ichikawa ${ }^{\text {a }}$, and Akira Matsuda*a \\ ${ }^{a}$ Faculty of Pharmaceutical Sciences, Hokkaido University, Kita-12, Nishi-6, Kita-ku, Sapporo 060-0812, Japan \\ ${ }^{b}$ Department of Molecular Microbiology and Immunology, Nagasaki University School of Medicine, Nagasaki 852-8501, Japan
}

ARTICLE INFO

\section{ABSTRACT}

Article history:

Received

Revised

Accepted

Available online

\section{Keyword 5:}

Epigenetic

Nucleic acids

5-formyl-2'-deoxycytidine

Covalent bond

DNA methyltransferase

Methylation at the $\mathrm{C} 5$ position of cytosine in a $\mathrm{CpG}$ dinucleotide is catalyzed by DNA cytosine-5 methyltransferase (DNMT) to give 5-methylCpG (mCpG), using $S$-adenosyl-Lmethionine (SAM) as the methyl group donor (Figure 1A). This modification has a profound effect on gene expression, particularly in gene promoter regions. ${ }^{1,2}$ One characteristic of tumor cells is their unusual DNA methylation patterns. There are a number of repetitive DNA sequences, and some genes are hypermethylated, leading to silencing of the gene. ${ }^{3-5}$ Demethylation of $\mathrm{mCpG}$ has been extensively studied, and teneleven translocation 1 (TET1) has been found to oxidize the methyl group in $\mathrm{mC}$ to give 5-hydroxymethylcytosine (hmC) as a first step in the demethylation pathway. ${ }^{6-10}$ In subsequent studies, it was shown that hmC is also a substrate of TET1, 2 and 3, with the reaction of $\mathrm{hmC}$ producing the further oxidized 5-substituted cytosine derivatives, 5-formylcytosine (fC) and 5carboxylcytosine (caC). ${ }^{11-15}$ Because $\mathrm{fC}$ and $\mathrm{caC}$ are good substrates of thymine-DNA glycosylase (TDG), the bases can be converted to an appropriate form to trigger base-excision repair (BER) to return to $\mathrm{CpG}$, the demethylated form (Figure 1C). ${ }^{16} \mathrm{It}$ was discovered that DNMT can catalyze the direct dehydroxymethylation of $\mathrm{hmC}^{17}$ and decarboxylation of $\mathrm{caC}$ to give unmodified cytosine in DNA. ${ }^{18}$ Thus, hmC, $\mathrm{fC}$ and $\mathrm{caC}$ are primarily believed to be intermediates in the demethylation pathway. ${ }^{19}$ However, hmC is believed to play an important role in epigenetic programming of the genome and regulation of tissuespecific gene expression and, therefore, could add another layer of complexity to the intricate network of epigenetic regulation. ${ }^{20,21}$ Recently, Bachman et al. reported that fC levels in mammalian DNA are not correlated with those of its precursors, $\mathrm{mC}$ and $\mathrm{hmC}$, or its metabolite $\mathrm{caC} .^{22}$ Many proteins, including transcriptional regulators, DNA repair factors and chromatin regulators, have been known to preferentially bind to ODNs containing fC compared to those containing only $\mathrm{mC}$ or hmC. ${ }^{23,24}$ X-ray crystallography of a duplex ODN containing (fCpG) revealed helical underwinding, and these conformational changes may directly control the recruitment of $\mathrm{fC}$ reading proteins. ${ }^{25}$ Therefore, fC may have functional roles in DNA that go beyond being simply a demethylation intermediate. Here, we found that an ODN containing $\mathrm{fC}$ in a $\mathrm{CpG}$ sequence reacts with DNMTs through the formation of a covalent bond, similarly to ODNs containing 5-aza-2'-deoxycytidine $\left(\mathrm{d}^{\mathrm{N}} \mathrm{C}\right),{ }^{26-28}$ 5-fluoro-2'deoxycytidine $\left(\mathrm{d}^{\mathrm{F}} \mathrm{C}\right)^{29,30}$ and zebularine. ${ }^{31}$ They act as suicide inhibitors for DNMTs by covalent bond formation between the C6-position of the base moieties and a catalytically essential Cys residue same as natural methylation mechanism (Figure 1B) after incorporation at the CpG site in DNA by DNA polymerases. ${ }^{17-19}$

Introduction of a formyl group at the $\mathrm{C} 5$-position of cytosine moiety gives an $\alpha, \beta$-unsaturated aldehyde, and the C6-position of the cytosine become more electron-deficient than that of cytosine itself. Therefore, we hypothesized that a DNMT would reacts with an ODN having fCpG sequences similar to $d^{\mathrm{N}} \mathrm{C}, \mathrm{d}^{\mathrm{F}} \mathrm{C}$ and zebularine (Figure 2A). 


\section{Results and Discussion}

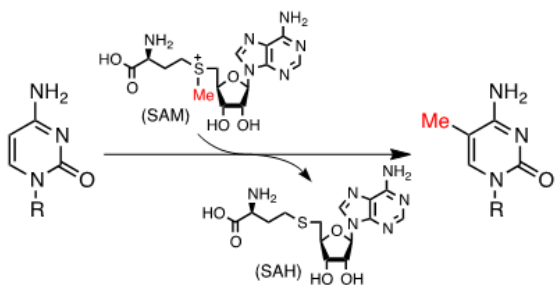

B
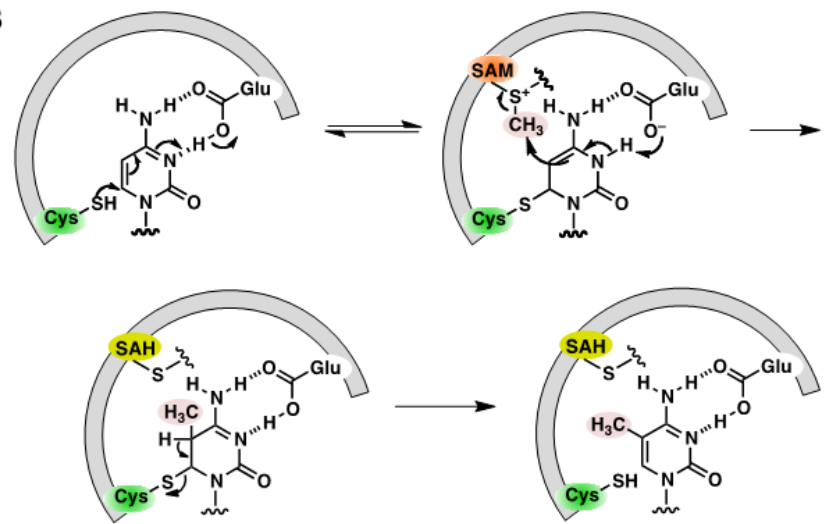

C

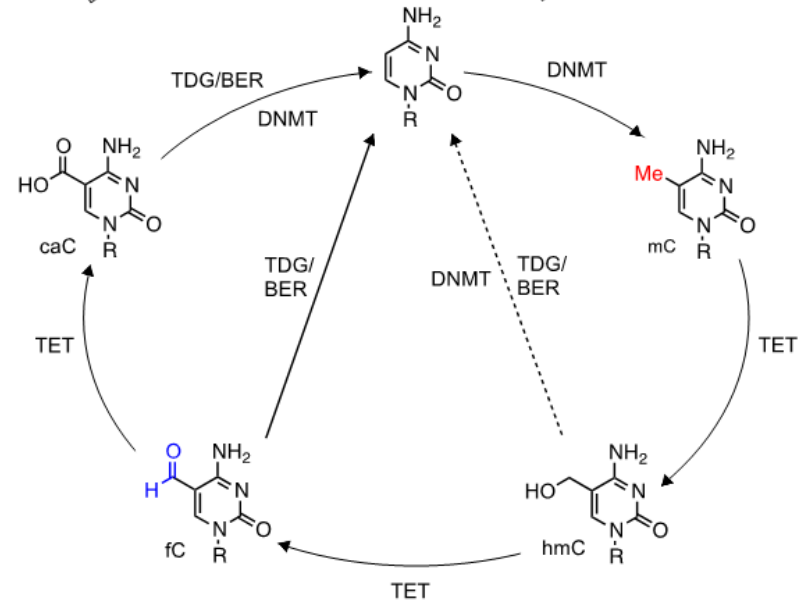

\begin{tabular}{|c|c|c|}
\hline & ODN-G & ODN-M \\
\hline \multicolumn{3}{|c|}{ 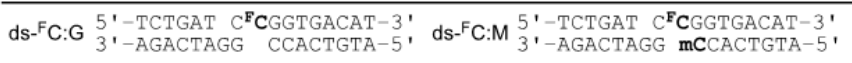 } \\
\hline ds-fC: & $\begin{array}{l}\text { 5'-TCTGAT CfCGGTGACAT-3' ds-fC: } \\
\text { 3'-AGACTAGG CCACTGTA-5' }\end{array}$ & $\begin{array}{l}\text { '-TCTGAT CfCGGTGACAT-3' } \\
\text { '-AGACTAGG mCCACTGTA-5' }\end{array}$ \\
\hline $\mathrm{s}-\mathrm{fC} \mathrm{C}^{*}: \mathrm{G}$ & $\begin{array}{l}\text { 5'-TCTGATIC CGGTGACAT-3', ds-fC } \\
3^{\prime}-\text {-AGACTA GG CCACTGTA-5, }\end{array}$ & \\
\hline
\end{tabular}

Figure 1. A) Methylation by DNA cytosine- 5 methyltransferases (DNMTs) with SAM as a cofactor. B) Plausible mechanism of cytosine methylation by DNMTs. C) Methylation of cytosine and demethylation pathways. ${ }^{17-19}$ D) Sequences of synthesized ODNs containing $\mathrm{d}^{\mathrm{F}} \mathrm{C}$, fC and 5-methyl-2'deoxycytidine $(\mathrm{mC})$.

First, we calculated electron density of the C6-position by Mulliken population analysis (Figure 3). Cytosine revealed at +0.11 , and ${ }^{\mathrm{F}} \mathrm{C}$ and ${ }^{\mathrm{N}} \mathrm{C}$ are more electron-negative as +0.15 and +0.29 , respectively. The formyl group also decreased the electron density at the C6-position as +0.16 quite similar to that of ${ }^{\mathrm{F}} \mathrm{C}$. Therefore, fC could react with the Cys residue at the active site of DNMT from the point of the electron negativity at the C6position. On the other hand, a size of a substituent at the C5position of cytosine in the $\mathrm{CpG}$ sequence is known to be important for recognition by DNMT. In a 5-halogenocytosine series, only the 5-fluorocytosine $\left({ }^{\mathrm{F}} \mathrm{C}\right)$ in the $\mathrm{CpG}$ sequence showed to react with DNMTs in the presence of SAM as shown in Figure 2B. Although a size of the 5-chloro and 5-bromo substituents is similar to that of a methyl group, the dsODNs containing these substituents were not recognized as inhibitors or
A

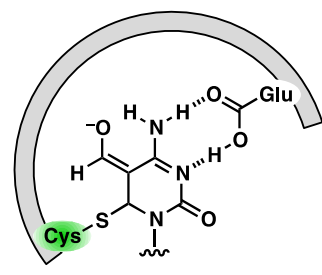

$\mathrm{fC}$
B

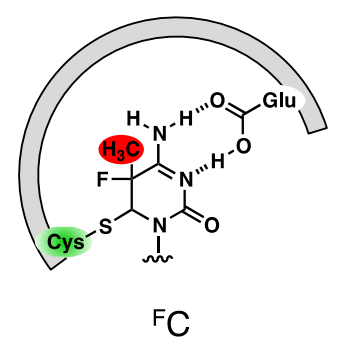

Figure 2. Plausible complex structures of A) $\mathrm{fC}$ and $\mathrm{B}$ ) ${ }^{\mathrm{F}} \mathrm{C}$ with DNMTs.

c

Figure 3. Mulliken population of $\mathrm{C},{ }^{\mathrm{F}} \mathrm{C},{ }^{\mathrm{N}} \mathrm{C}$ and $\mathrm{fC}$ at the C6-position calculated by Jaguar 7.7.

substrates by DNMTs, due might be sterical crash with the Pro in the active site. ${ }^{32}$ A size of the formyl group is sterically less hindered and planar by the $\mathrm{sp}^{2}$ carbon. Therefore, we synthesized ODN containing fC (ODN-fC) for the examination of the reaction with DNMTs.

The ODNs containing $\mathrm{fC}(\mathrm{ODN}-\mathrm{fC})$ were prepared using a method we previously described during studies of DNA oxidative lesions. ${ }^{33}$ ODN $-{ }^{\mathrm{F}} \mathrm{C}$ was used for control experiments as a covalent bond-forming ODN, and complementary ODN-G and ODN-M were also synthesized. To investigate the interaction of ODN-fC with DNMT, we first studied a bacterial DNMT, M.HpaII, from Haemophilus parainfluenzae. M.HpaII typically methylates the internal 2'-deoxycytidine in the target sequence 5'CEGG-3', but in our studies, fC was substituted in place of the internal 2'-deoxycytidine (ODN-fC). Annealing ODN-G with 5'${ }^{32} \mathrm{P}$-labeled ODN-fC or ODN- ${ }^{\mathrm{F}} \mathrm{C}$ gave the double-stranded (ds)fC: $\mathrm{G}$ and ds- ${ }^{\mathrm{F}} \mathrm{C}: \mathrm{G}$, respectively (Figure 1D). Each ds-ODN was incubated with 4 equiv. of M.HpaII at $37{ }^{\circ} \mathrm{C}$ for 5-60 min. The reactions were quenched with loading buffer containing $7 \mathrm{M}$ urea, and the reaction mixture was analyzed by denaturing polyacrylamide gel electrophoresis (PAGE). The reaction with ds-fC:G showed rapid and efficient formation of an ODNM.HpaII complex, giving greater than $90 \%$ yield after $5 \mathrm{~min}$ reaction time (Figure 4A, lane 1). The formyl group was allowed to recognize by the DNMT from our experiments. A formyl group (van Der Waals surface (vDW); 34.1 by Maestro 10 software) is sterically smaller than hydroxymethyl (vDW; 41.4) and carboxyl (vDW; 39.6) groups and a same size as a methyl group (vDW; 33.2 ) by its $\mathrm{sp}^{2}$ orbital and hydrogen substituent. This association rate is comparable to that of a previously reported disulfide-based DNA probe. ${ }^{34}$ The high binding affinity of the ODN may cause non-sequence-specific binding to DNMTs. To investigate whether formation of the covalent linkage between ODN-fC and M.HpaII is sequence specific or not, we examined ODN-fC* ${ }^{*}$, in which the external dC in 5'-CCGG-3' was replaced with fC (Figure 1D). In this case, M.HpaII did not form a complex with ds-fC*:G/M at all (Figure S1). Therefore, the methyltransferase binds to ds-fC: $\mathrm{G}$ with a sequence specific manner. On the other hand, ${ }^{-}{ }^{\mathrm{F}} \mathrm{C}: \mathrm{G}$ showed a band corresponding to a complex with M.HpaII in $40 \%$ yield after 60 min reaction time (Figure 4A, lane 8). It was reported that ODNs containing $\mathrm{d}^{\mathrm{N}} \mathrm{C}$ (decitabine, a clinically approved drug for treatment of myelodysplastic syndrome) in a $\mathrm{CpG}$ sequence instead of cytosine had a high rate of a complex formation with 
M.HhaI in both the absence and presence of SAM and $S$ adenosyl-L-homocysteine (SAH). ${ }^{27,28}$ This is important because the SAM/SAH ratio is different in each tissue, ${ }^{35}$ and a cofactorindependent inhibitor is desired for clinical use. As shown in Figure $4 \mathrm{~B}$, ds- ${ }^{\mathrm{F}} \mathrm{C}: \mathrm{G}$ formed a complex with M.HpaII only in the presence of SAM (lanes 2-4). Moreover, the complex formation of ds-fC: $\mathrm{G}$ occurred in high yield and independent of cofactors such as SAM and SAH (lanes 5-7). Therefore, DNMT binds to ds-fC: $\mathrm{G}$ more efficiently than $\mathrm{ds}^{-} \mathrm{C}: \mathrm{G}$, and this occurs in the presence or absence of any cofactors. We next investigated whether ds-fC: $\mathrm{G}$ forms a covalent complex or not.

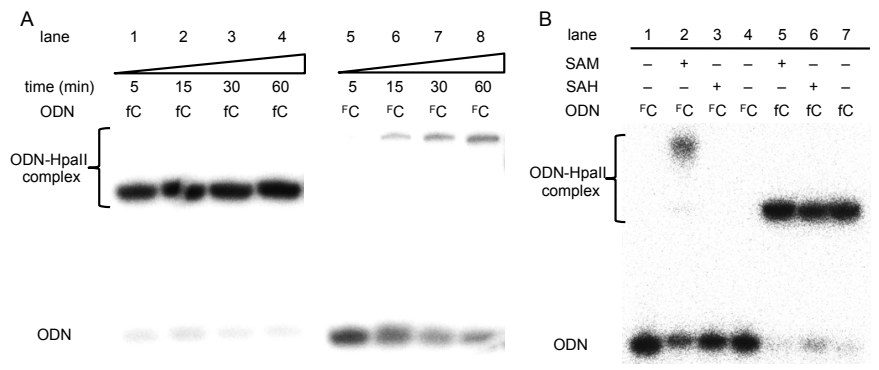

Figure 4. Gel shift assay of $\mathrm{ds}-\mathrm{fC}: \mathrm{G}$ and $\left.\mathrm{ds}^{-}{ }^{\mathrm{F}} \mathrm{C}: \mathrm{G}: \mathrm{A}\right) \mathrm{ODN}-\mathrm{fC}$ and ODN${ }^{\mathrm{F}} \mathrm{C}$ were $5^{\prime}{ }^{32} \mathrm{P}$ labeled and annealed with $\mathrm{ODN}-\mathrm{G}$. The reactions were performed with $0.1 \mu \mathrm{M}$ ds-fC:G or ds- ${ }^{\mathrm{F}} \mathrm{C}: \mathrm{G}$ and $240 \mu \mathrm{M}$ SAM by incubating at $37^{\circ} \mathrm{C}$ for 5-60 min with $0.4 \mu \mathrm{M}$ M.HpaII in $50 \mathrm{mM}$ Tris- $\mathrm{HCl}$ (pH 7.5), $10 \mathrm{mM}$ EDTA and $5 \mathrm{mM} \beta$-mercaptoethanol, and analyzed by denaturing PAGE $(8 \%, 140 \mathrm{~V}, 1 \mathrm{~h})$. Lanes 1 and $5 ; 5 \mathrm{~min}$, lanes 2 and $6 ; 15$ min, lanes 3 and 7; $30 \mathrm{~min}$, lanes 4 and 8; $60 \mathrm{~min}, \mathrm{~B})$ The reactions were performed with $0.1 \mu \mathrm{M}$ ds- ${ }^{\mathrm{F}} \mathrm{C}: \mathrm{G}$ or ds-fC: $\mathrm{G}$ and $240 \mu \mathrm{M}$ SAM or SAH (or no cofactor) by incubating at $37^{\circ} \mathrm{C}$ for $2 \mathrm{~h}$ with $0.4 \mu \mathrm{M}$ M.HpaII in $50 \mathrm{mM}$ Tris- $\mathrm{HCl}(\mathrm{pH} 7.5), 10 \mathrm{mM}$ EDTA and $5 \mathrm{mM} \beta$-mercaptoethanol, and analyzed by denaturing PAGE $(8 \%, 140 \mathrm{~V}, 1 \mathrm{~h})$. Lane 1 ; control ds- ${ }^{\mathrm{F}} \mathrm{C}: \mathrm{G}$, lane 2; ds- ${ }^{\mathrm{F}} \mathrm{C}: \mathrm{G}$ with SAM, lane 3 ; ds- ${ }^{\mathrm{F}} \mathrm{C}: \mathrm{G}$ with $\mathrm{SAH}$, lane 4 ; ds- ${ }^{\mathrm{F}} \mathrm{C}: \mathrm{G}$ without SAM and SAH, lane 5; ds-fC:G with SAM, lane 6; ds-fC:G with $\mathrm{SAH}$, lane 7; ds-fC:G without SAM and SAH.

The reversibility of the ODN-M.HpaII complex was studied in the presence of a large excess of non-labeled exchanger ds-fC: $\mathrm{G}$ (Figure S2). The complex formed with SAM or SAH (Figure 4B, lanes 5 and 6) was not disrupted by the addition of 100 equiv. of non-labeled ds-fC: $\mathrm{G}$ after $48 \mathrm{~h}$ of incubation, while the ${ }^{32} \mathrm{P}-$ labeled complex was disrupted $\left(\mathrm{t}_{1 / 2} 56.2 \mathrm{~h}\right)$ in the absence of cofactors (Figure 4B, lane 7 and Figure S2B).

Finally, mouse recombinant Dnmt $1^{36}$ was studied for complex formation with ds-fC:M and ds- ${ }^{\mathrm{F}} \mathrm{C}: \mathrm{M}$. While ds- ${ }^{\mathrm{F}} \mathrm{C}: \mathrm{M}$ formed the complex in $19 \%$ yield after a 30 min reaction (Figure $5 \mathrm{~A}$, lane 4 ), the rate of complex formation with ds-fC:M was much faster with over $80 \%$ yield after a $30 \mathrm{~min}$ reaction (Figure $5 \mathrm{~A}$, lane 9). The effect of cofactors on complex formation was also studied as described previously with the bacterial enzyme. Complex formation with ds-fC:M did not require any cofactors and the product was stable in denaturing PAGE, while the complex with ds- ${ }^{\mathrm{F}} \mathrm{C}$ :M required SAM for stable complex formation (Figure S3). Although many types of DNA binding proteins are present in the nuclear extract of MCF-7 cells, only one ${ }^{32} \mathrm{P}$-labeled ODNprotein complex band was observed on PAGE when ds-fC:M was incubated with the extract (Figure 5B), suggesting that ds$\mathrm{fC}: \mathrm{M}$ binds strongly and selectively to Dnmt1 in cells.

In summary, we have synthesized an ODN containing 5formyl-2'-deoxycytidine (fC) instead of 2'-deoxycytidine in a $\mathrm{CpG}$ sequence. $\mathrm{fC}$ is known to be an intermediate in the oxidative demethylation pathway of an $\mathrm{mCpG}$ sequence. It was found that ds-fC: $\mathrm{G}$ is capable of highly efficient formation of ODN-DNMT
A
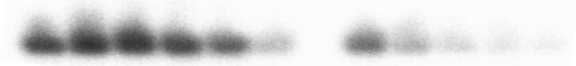

Figure 5. Gel shift assay of ds- ${ }^{\mathrm{F}} \mathrm{C}: \mathrm{M}$ and ds-fC:M: A) $\mathrm{ODN}-{ }^{\mathrm{F}} \mathrm{C}$ and $\mathrm{ODN}-$ fC were $5^{\prime}-{ }^{32} \mathrm{P}$ labeled and annealed with ODN-G. The reactions were performed with $0.1 \mu \mathrm{M}$ ds- ${ }^{\mathrm{F}} \mathrm{C}: \mathrm{M}$ or ds-fC:M and $240 \mu \mathrm{M}$ SAM by incubating at $37{ }^{\circ} \mathrm{C}$ for $5-120$ min with $0.4 \mu \mathrm{M}$ mouse recombinant Dnmt 1 in $50 \mathrm{mM}$ Tris- $\mathrm{HCl}$ (pH 7.5), $1 \mathrm{mM}$ EDTA, $10 \mathrm{mM} \mathrm{NaCl}, 5 \mathrm{mM} \beta-$ mercaptoethanol, $5 \%$ glycerol and $20 \mu \mathrm{g} / \mathrm{mL}$ BSA, and analyzed by denaturing PAGE $(8 \%, 140 \mathrm{~V}, 1 \mathrm{~h})$. Lanes 2 and $7 ; 5$ min, lanes 3 and $8 ; 15$ min, lanes 4 and 9; $30 \mathrm{~min}$, lanes 5 and 10; $60 \mathrm{~min}$, lanes 6 and $11 ; 120$ min. B) EMSA of ds-fC:M with nuclear extract of MCF-7 cells. The dsfC:M $(0.2 \mu \mathrm{M})$ was incubated with nuclear extract of MCF-7 cells (2 $\mu \mathrm{g} / \mathrm{mL}$ ) at $37{ }^{\circ} \mathrm{C}$ for $120 \mathrm{~min}$ and analyzed by PAGE. Lane 1; ds-fC:M without nuclear extract of MCF-7 cells, lane 2; ds-fC:G with nuclear extract of MCF-7 cells.

complex with both bacterial DNMT (M.HpaII) and mouse recombinant Dnmt1 in the absence of any cofactors such as SAM and SAH. Therefore, our research suggests that $\mathrm{fC}$ in a $\mathrm{CpG}$ sequence of DNA may not be just an intermediate in the demethylation pathway, waiting for repair with the TDG/BER system to furnish the demethylation of $\mathrm{mCpG}$ to $\mathrm{CpG}$, but may play a role in the DNA methylation/demethylation regulation pathway by specific and efficient complex formation with DNMT.

\section{Acknowledgments}

This work was supported in part by Grant-in-Aid for Scientific Research (A) (Grant No. 23249008), (C) (Grant No. 25410165) from from Japan Society for the Promotion of Science (JSPS).

\section{References and notes}

1. Jones, P. A.; Baylin, S. B. Nat. Rev. Genet. 2002, 3, 415-428.

2. Goll, M. G.; Bestor, T. H. Annu. Rev. Biochem. 2005, 74, 481-514.

3. Egger, G.; Liang, G.; Aparicio, A.; Jones, P. A. Nature 2004, 429, 457-463.

4. Robertson, K. D. Nat. Rev. Genet. 2005, 6, 597-610.

5. Jones, P. A.; Baylin, S. B. Cell 2007, 128, 683-692.

6. Kriaucionis, S.; Heintz, N. Science 2009, 324, 929-930.

7. Tahiliani, M.; Koh, K. P.; Shen, Y.; Pastor, W. A.; Bandukwala, H.; Brudno, Y.; Agarwal, S.; Iyer, L. M.; Liu, D. R.; Aravind, L.; Rao, A. Science 2009, 324, 930-935.

8. Münzel, M.; Globisch, D.; Brückl, T.; Wagner, M.; Welzmiller, V.; Michalakis, S.; Müller, M.; Biel, M.; Carell, T. Angew. Chem. Int. Ed. 2010, 49, 5375-5377.

9. Branco, M. R.; Ficz, G.; Reik, W. Nat. Rev. Genet. 2012, 13, 7-13.

10. Penn, N. W.; Suwalski, R.; O’riley, C.; Bojanowski, K.; Yura, R. Biochem. J. 1972, 126, 781-790.

11. Globisch, D.; Münzel, M.; Müller, M.; Michalakis, S.; Wagner, M.; Koch, S.; Brückl, T.; Biel, M.; Carell, T. PLoS ONE 2010, 5, e15367.

12. Ito, S.; Shen, L.; Dai, Q.; Wu, S. C.; Collins, L. B.; Swenberg, J. A.; He, C.; Zhang, T. Science 2011, 333, 1300-1303. 
13. Pfaffeneder, T.; Hackner, B.; Truss, M.; Münzel, M.; Müller, M.; Deiml, C. A.; Hagemeier, C.; Carell, T. Angew. Chem. Int. Ed. 2011, 50, 7008-7012.

14. He, Y.-F.; Li, B.-Z.; Li, Z.; Liu, P.; Wang, Y.; Tang, Q.; Ding, J.; Jia, Y.; Chen, Z.; Li, L.; Sun, Y.; Li, X.; Dai, Q.; Song, C.-X.; Zhang, K.; He, C.; Xu, G.-L. Science 2011, 333, 1303-1307.

15. Zhang, L.; Lu, X.; Lu, J.; Liang, H.; Dai, Q.; Xu, G.-L.; Luo, C.; Jiang, H.; He, C. Nat. Chem. Biol. 2012, 8, 328-330.

16. Maiti, A.; Drohat, A. C. J. Biol. Chem. 2011, 286, 35334-35338.

17. Liutkevič̌ute, Z.; Liutkevič̌ute, G.; Masevič̌us, V.; Daujotyte, D.; Klimasăuskas, S. Nat. Chem. Biol. 2009, 5, 400-402.

18. Liutkevič̌ute, Z.; Kriukiene, E.; Licy̌te, J.; Rudyte, M.; Urbanavicǐute, G.; Klimasăuskas, S. J. Am. Chem. Soc. 2014, 136, 5884-5887.

19. Kubik, G.; Summerer, D. ACS Chem. Biol. 2015, 10, 1580-1589.

20. Kraus, T. F.; Globisch, D.; Wagner, M.; Eigenbrod, S.; Widmann, D.; Münzel, M.; Pfaffeneder, T.; Hackner, B.; Feaden, W.; Schüller, U.; Carell, T.; Kretzschmar, H. A. Int. J. Cancer 2012, 131, 1577-1590.

21. Yang, H.; Liu, Y.; Bai, F.; Zhang, J. Y.; Ma, S. H.; Liu, J.; Xu, Z. D.; Zhu, H. G.; Ling, Z. Q.; Ye, D.; Guan, K. L.; Xiong, Y. Oncogene 2013, 32, 663-669.

22. Bachman, M.; Uribe-Lewis, S.; Yang, X.; Burgess, H. E.; Iurlaro, M.; Reik, W.; Murrell, A.; Balasubramanian, S. Nat. Chem. Biol. 2015, 11, 555-557.

23. Iurlaro, M.; Ficz, G.; Oxley, D.; Raiber, E.-A.; Bachman, M.; Booth, M. J.; Andrews, S.; Balasubramanian, S.; Reik, W. Gen. Biol. 2013, 14, R119.

24. Spruijt, C. G.; Gnerlich, F.; Smits, A. H.; Pfaffeneder, T.; Jansen, P. W. T. C.; Bauer, C.; Münzel, M.; Wagner, M.; Müller, M.; Khan, F.; Eberi, H. C.; Mensinga, A.; Brinkman, A. B.; Lephikov, K.; Müller, U.; Walter, J.; Boelens, R.; van Ingen, H.; Leonhardt, H.; Carell, T.; Vermeulen, M. Cell 2013, 152, 1146-1159.
25. Raiber, E.-A.; Murat, P.; Chirgadze, D. Y.; Beraldi, D.; Luisi, B. F.; Balasubramanian, S. Nat. Struct. Mol. Biol. 2015, 22, 44-49.

26. Momparler, R. L.; Momparler, L. F.; Samson, J. Leuk. Res. 1984, 8, 1043-1049.

27. Christman, J. K. Oncogene 2002, 21, 5483-5495.

28. Kuch, D.; Schermelleh, L.; Manetto, S.; Leonhardt, H.; Carell, T. Angew. Chem. Int. Ed. 2008, 47, 1515-1518.

29. Chen, L.; MacMillan, A. M.; Chang, W.; Ezaz-Nikpay, K.; Lane, W. S.; Verdine, G. L. Biochemistry 1991, 30, 11018-11025.

30. Santi, D. V.; Garrett, C. E.; Barr, P. J. Cell 1983, 33, 9-10.

31. Zhou, L.; Cheng, X.; Connolly, B. A.; Dickman, M. J.; Hurd, P. J.; Hornby, D. P. Mol. Biol. 2002, 321, 591-599.

32. Valinluck, V.; Wu, W.; Liu, P.; Neidigh, J. W.; Sowers, L. C. Chem. Res. Toxicol. 2006, 19, 556-562.

33. Karino, N.; Ueno, Y.; Matsuda, A. Nucleic Acids Res. 2001, 29, 2456-2463.

34. Shigdel, U. K.; He, C. J. Am. Chem. Soc. 2008, 130, 17634-17635.

35. Chen, N. C.; Yang, F.; Capecci, L. M.; Gu, Z.; Schafer, A. I.; Durante, W.; Yang, X.; Wang, H. The FASEB J. 2010, 24, 28042817.

36. Shimamura, S.; Ishikawa, F. Cancer Sci. 2008, 99, 1960-1966.

\section{Supplementary Material}

Supplementary data associated with this article can be found, in the online version. 